\title{
ARTIGOS
}

\section{Custo adaptativo da indução de resistência em feijoeiro mediada pela rizobactéria Bacillus cereus ou acibenzolar-S-metil: atividade de enzimas, síntese de fenóis e lignina e biomassa.}

\author{
Odair José Kuhn ${ }^{1} \&$ Sérgio Florentino Pascholati ${ }^{2}$
}

${ }^{1}$ Universidade Federal do Pampa, Campus Itaqui, Rua Luiz Joaquim de Sá Brito, s/n, Itaqui, RS.; ${ }^{2}$ Esalq/USP, Setor de Fitopatologia, Av. Pádua dias 11, Cx. Postal 9, CEP 13418-900, Piracicaba -SP, Fone: (19) 34294124

Autor para correspondência: Sérgio Florentino Pascholati (sfpascho@esalq.usp.br)

Data de chegada: 01/02/2007. Aceito para publicação em: 02/10/2009.

\section{RESUMO}

Kuhn, O.J. \& Pascholati, S.F.. Custo adaptativo da indução de resistência em feijoeiro mediada pela rizobactéria Bacillus cereus ou acibenzolarS-metil: atividade de enzimas, síntese de fenóis e lignina e biomassa. Summa Phytopathologica, v.36, n.2, p.107-114, 2010.

Plantas que utilizam recursos para defesa na ausência de pragas ou patógenos, arcarão com custos energéticos que podem refletir na sua produtividade. Assim, teve-se por objetivo avaliar os custos adaptativos da indução de resistência, antes da chegada do patógeno, em feijoeiro induzido por um indutor biótico (Bacillus cereus) e um abiótico (acibenzolar-S-metil, ASM), em 2, 3 ou 4 aplicações distribuídas ao longo do ciclo da cultura. Avaliou-se o efeito protetor contra a bactéria Xanthomonas axonopodis pv. phaseoli, além da atividade de peroxidase, quitinase, $\beta$-1,3-glucanase, síntese de lignina, fenóis e crescimento com base na matéria seca. Observou-se que os indutores protegeram a cultura contra $X$. axonopodis pv. phaseoli com base na redução da severidade. O ASM aumentou a atividade de peroxidase, quitinase e $\beta$-1,3-glucanase, enquanto que o $B$. cereus aumentou apenas a peroxidase. O ASM aumentou a síntese de lignina e $B$. cereus não, enquanto que ASM diminuiu teor de fenóis e B. cereus não. O ASM reduziu a biomassa da planta, o que não ocorreu em plantas induzidas por $B$. cereus. Portanto, a resistência induzida por ASM apresenta elevado custo associado, enquanto que por B. cereus apresenta baixo custo, necessitando a indução de resistência ser melhor explorada e estudada para potencializar seu uso em feijoeiro.

Palavras-chave adicionais: Quitinase; $\beta$-1,3-glucanase; peroxidase; Phaseolus vulgaris; metabolismo; produtividade.

\begin{abstract}
Kuhn, O.J. \& Pascholati, S.F.. Fitness cost of induced resistance in bean plants by the rhizobacteria Bacillus cereus or acibenzolar-S-methyl: enzymes activities, phenol and lignin synthesis, and biomass. Summa Phytopathologica, v.36, n.2, p.107-114, 2010.

Plants that use resources to defend themselves in the absence of pests or pathogens will pay off with energy costs that can reflect in the productivity. Thus, the objective of this work was to evaluate the fitness costs of the resistance induced in bean plants, before the presence of the pathogen, by using biotic (Bacillus cereus) and abiotic (acibenzolar-S-methyl, ASM) inducers, applied 2, 3 or 4 times during the cycle of the culture. The protecting effect was evaluated against the bacterium Xanthomonas axonopodis pv. phaseoli. The activities of peroxidase, chitinase and $\beta$-1,3-glucanase, lignin and phenol

synthesis and plant growth were evaluated too. It was observed that the inducers protected the bean plants against $X$. axonopodis $\mathrm{pv}$. phaseoli. The ASM increased the activity of peroxidase, chitinase and $\beta$-1,3-glucanase, while $B$. cereus only increased peroxidase activity. Unlike $B$. cereus, the ASM increased lignin synthesis and decreased phenolic compound content and plant growth. Therefore, the resistance induced by ASM represents high fitness costs for bean plants, while the resistance induced by $B$. cereus represents low cost and its potential use can be explored.
\end{abstract}

Keywords: Chitinase $\beta$-1,3-glucanase; peroxidase; Phaseolus vulgaris; metabolism; yield.

O controle de doenças de plantas é o objetivo prático mais importante da fitopatologia, que justifica o alto investimento em pesquisa e desenvolvimento de produtos e técnicas, visando cumprir esse objetivo. No entanto, a busca por alta produtividade com técnicas de fácil uso e eficiência, fez com que os fungicidas passassem a ser largamente utilizados, ao custo de grande impacto ambiental. Por outro lado, no final do século passado, as pesquisas se intensificaram no tocante ao uso da indução de resistência, e comprovaram a sua eficiência na redução da intensidade de várias doenças. No entanto, poucos pesquisadores se preocuparam em avaliar a produtividade das culturas em meio a esse fenômeno, pois uma tecnologia para ser aceita e adotada necessita ser economicamente viável.

Esses aspectos são importantes, visto que, as plantas apresentam um sistema de defesa latente, com a finalidade de economizar energia e substrato, que pode ser ativado com a chegada do patógeno. Ao contrário, a resistência constitutiva representa um custo real para a planta, que aloca seus limitados recursos na produção de defesas, independente da presença do patógeno. Na presença do patógeno, o investimento em defesa deve valer a pena e as plantas induzidas serem beneficiadas (8). Assim, a resistência induzida em condições naturais representará custo apenas na presença do patógeno (12), e, mesmo com a chegada deste, há uma compensação pelo atraso temporal na 
expressão da defesa, alocando recursos para este propósito somente quando necessários (5). Porém, plantas que alocam seus recursos em defesa na ausência de patógenos podem arcar com custos que refletirão na produtividade, uma vez que as alterações metabólicas que levam à resistência possuem um custo adaptativo associado, o qual pode pesar mais do que o benefício (15).

Nesse contexto, é preciso considerar ainda que o efeito protetor da resistência induzida, dependendo do indutor e da planta utilizados, pode durar desde poucos dias até por todo o ciclo da planta (4). Portanto, podem ser necessárias várias aplicações durante o ciclo da cultura, como no caso do tomateiro, onde a aplicação de acibenzolarS-metil (ASM) é semanal, mantendo as plantas ativadas por todo o ciclo (17). Essa manutenção do estado ativado pode ser custosa para as plantas, uma vez que a inducibilidade pode ser considerada como um mecanismo de economia da planta.

Em algumas pesquisas envolvendo indução de resistência em diferentes sistemas hospedeiro-patógenos, têm-se observado um ganho de produtividade, fato que indica um custo menor do que o benefício. Porém, em outros casos, não há incrementos na produtividade, ou até há redução da mesma, ainda com drástica redução da doença $(9,10,13$, 22). Portanto, a expressão da defesa pode reduzir a produtividade, a ponto de ser o custo maior do que o benefício? E em que condição isso pode acontecer? Existem diferenças entre indutores bióticos e abióticos em relação ao custo adaptativo da indução de resistência? Estas são perguntas que precisam ser respondidas para se redirecionar as pesquisas e o uso desta tecnologia.

Neste trabalho foram conduzidos experimentos objetivando verificar alterações na atividade de proteínas-RP (peroxidase, quitinase e $\beta$-1,3-glucanase), síntese de lignina e compostos fenólicos, mecanismos de defesa contra patógenos, correlacionando-os com o crescimento do feijoeiro expressando resistência induzida contra Xanthomonas axonopodis pv. phaseoli, mediada por ASM (um indutor químico), e por B. cereus, (um indutor biológico), aplicados 2,3 ou 4 vezes ao longo do ciclo da cultura e na ausência do patógeno.

\section{MATERIAL E MÉTODOS}

\section{Obtenção e manutenção dos microrganismos}

Xanthomonas axonopodis pv. phaseoli foi isolada de plantas de feijão, sendo cultivada em meio 523 de Kado \& Heskett (16). As culturas foram mantidas a $25^{\circ} \mathrm{C}$ no escuro por período de $96 \mathrm{~h}$, sendo que para o processo de inoculação foi preparada suspensão de células ajustadas para $10^{8}$ células $\mathrm{mL}^{-1}$. Por sua vez, o isolado de Bacillus cereus, com comprovada ação na indução de resistência contra Alternaria solani, Corynespora cassiicola, Stemphilium solani, Oidium lycopersici $\mathrm{e}$ Xanthomonas campestris pv. vesicatoria (24), foi cultivado em meio 523 de Kado \& Heskett por 48 horas na ausência de luz a 25 ${ }^{\circ} \mathrm{C}$, preparando-se suspensão ajustada para $10^{8}$ células por $\mathrm{mL}$ a partir da lavagem das placas de petri (16).

\section{Cultivo em casa de vegetação com aplicação dos indutores}

O feijão (cv. Carioca Tybatã) foi cultivado em vasos de $4 \mathrm{~L}$ contendo mistura de solo, areia e matéria orgânica (2:1:2) autoclavados (uma hora a $121{ }^{\circ} \mathrm{C}$, sendo repetida a operação 24 h após), adubados com 1,5 g por vaso da fórmula 04-14-08 e mantidos em casa de vegetação. Os tratamentos foram dispostos em esquema fatorial $2 \times 4$, considerando dois indutores e quatro formas de aplicação. Os indutores foram representados por ASM, aplicando-se com auxílio de pulverizador, $10 \mathrm{~mL}$ de solução por planta, na concentração de $50 \mathrm{mg}$ i.a. $\mathrm{L}^{-1}$ e $10 \mathrm{~mL}$ de suspensão de células de $B$. cereus por planta na concentração de $10^{8}$ ufc $\mathrm{mL}^{-1}$ na parte aérea. As plantas sem a aplicação dos indutores (controle) foram pulverizadas com $10 \mathrm{~mL}$ de água destilada. Para cada indutor foram efetuadas as seguintes aplicações: Tratamento 1, aos 14, 28, 42 e 56 dias após a emergência (dae); Tratamento 2, aos 14, 28 e 42 dae; Tratamento 3, aos 14 e 42 dae e Tratamento 4, sem aplicações (controle). Cada tratamento foi composto de quatro repetições com cinco vasos por repetição, um para cada coleta de material, cada vaso continha duas plantas, totalizando 160 unidades experimentais. Os tratamentos que receberam três e duas aplicações foram tratados com água destilada na época em que não deveriam receber os indutores. $\mathrm{O}$ experimento foi conduzido de agosto a dezembro de 2004 e repetido da mesma maneira de fevereiro a junho de 2005, no campo experimental do Setor de Fitopatologia da Escola Superior de Agricultura "Luiz de Queiroz".

\section{Verificação da sistematicidade do controle}

Em casa de vegetação foram cultivadas plantas de feijão, em vasos de $3 \mathrm{~L}$ e aos 10 dias após a emergência dispensou-se $10 \mathrm{~mL}$ dos agentes indutores, suspensão de propágulos de B. cereus $\left(10^{8} \mathrm{ufc} \mathrm{mL}\right.$ ${ }^{1}$ ) ou ASM (50 mg i.a. $\left.\mathrm{mL}^{-1}\right)$, sobre as folhas monofoliadas, sendo água destilada o tratamento controle. Três dias após, quando a planta já apresentava a primeira folha trifoliada, foi inoculada a bactéria $X$. axonopodis pv. phaseoli, pela pulverização de suspensão de células $\left(10^{8} \mathrm{ufc}^{\mathrm{mL}} \mathrm{L}^{-1}\right)$, preparada a partir de colônias com quatro dias de crescimento. Aos 15 dias após a inoculação foi avaliada a severidade do crestamento bacteriano comum, pela quantificação da área lesionada, com o auxílio do software QUANT v. 1.0.2 (27). Cada tratamento foi composto de 20 repetições.

\section{Obtenção e armazenamento das amostras de tecido foliar}

Para a realização das análises bioquímicas, folhas de feijoeiro completamente expandidas foram coletadas das plantas de cada tratamento a partir do décimo quarto dia após a germinação, por ocasião da primeira aplicação dos tratamentos, a segunda coleta sete dias após, a terceira coleta 21 dias após, a quarta coleta 35 dias após e a quinta coleta 49 dias após, dessa forma as coletas foram realizadas sempre sete dias após cada aplicação dos tratamentos. Essas amostras foram acondicionadas em caixa térmica, contendo gelo, e transportadas para o laboratório para pesagem e processamento, visando o armazenamento em freezer $\left(-20^{\circ} \mathrm{C}\right)$ para posterior análise.

\section{Obtenção dos extratos protéicos}

As amostras de folhas $(0,5 \mathrm{~g})$ foram homogeneizadas mecanicamente em $4 \mathrm{~mL}$ de tampão acetato de sódio $100 \mathrm{mM}(\mathrm{pH}$ 5,0 ), com auxílio de almofariz. O homogenato foi centrifugado a $20.000 \mathrm{~g}$ durante 25 min a $4{ }^{\circ} \mathrm{C}$, e o sobrenadante obtido considerado como extrato enzimático para a determinação da atividade de peroxidase, quitinase e $\beta$-1,3-glucanase, e o conteúdo protéico.

\section{Atividade de peroxidase}

A atividade de peroxidase foi determinada à $30^{\circ} \mathrm{C}$, pelo método espectrofotométrico direto, pela medida da conversão do guaiacol em tetraguaiacol a $470 \mathrm{~nm}$ (18). A mistura da reação continha $0,1 \mathrm{~mL}$ do extrato protéico e $2,9 \mathrm{~mL}$ de solução com $250 \mu \mathrm{L}$ de guaiacol e $306 \mu \mathrm{L}$ de peróxido de hidrogênio em $100 \mathrm{~mL}$ de tampão fosfato $0,01 \mathrm{M}(\mathrm{pH}$ $6,0)$. A cubeta de referência continha $3 \mathrm{~mL}$ da solução com guaiacol e peróxido de hidrogênio. A atividade da peroxidase foi expressa como atividade específica (unidades de absorbância $\min ^{-1} \mathrm{mg}^{-1}$ proteína). 


\section{Atividade de quitinase}

A atividade de quitinase foi avaliada pela liberação de fragmentos solúveis de "CM-chitin-RBV", a partir de quitina carboximetilada marcada com remazol brilhante violeta (CM-Quitin-RBV $4 \mathrm{mg} \mathrm{mL}^{-1}$, Loewe Biochemica $\mathrm{GmbH}$ ) (26). Para tanto, $200 \mu \mathrm{L}$ do extrato protéico foi misturado com $600 \mu \mathrm{L}$ do mesmo tampão de extração e $200 \mu \mathrm{L}$ de "CM-chitin-RBV" $\left(2,0 \mathrm{mg} \mathrm{mL}^{-1}\right)$. Após incubação por $20 \mathrm{~min}$ a $40^{\circ} \mathrm{C}$, a reação foi paralisada com a adição de $200 \mu \mathrm{L}$ de solução de $\mathrm{HCl} 1 \mathrm{M}$, seguida de resfriamento em gelo e centrifugação a $10.000 \mathrm{~g} / 5 \mathrm{~min}$. A absorbância a $550 \mathrm{~nm}$ do sobrenadante foi determinado tendo-se tampão de extração na cubeta de referência. Os resultados foram expressos em unidades de absorbância $\min ^{-1} \mathrm{mg}^{-1}$ proteína, descontando-se os valores de absorbância do controle $(800 \mu \mathrm{L}$ de tampão de extração + $200 \mu \mathrm{L}$ de "CM-chitin-RBV").

\section{Atividade de $\beta$-1,3-glucanase}

Para a determinação espectrofotométrica da atividade de $\beta-1,3-$ glucanase nos extratos foi utilizado como substrato uma solução de carboximetilcurdlan-remazol brilhante azul (CM-Curdlan-RBB $4 \mathrm{mg}$ $\mathrm{mL}^{-1}$, Loewe Biochemica $\mathrm{GmbH}$ ), de acordo com metodologia desenvolvida por Wirth \& Wolf (28) e procedimento descrito por Guzzo \& Martins (11). Para tanto, $200 \mu \mathrm{L}$ do extrato protéico foi misturado com $600 \mu \mathrm{L}$ do mesmo tampão de extração e $200 \mu \mathrm{L}$ de CM-curdlan-RBB $\left(4,0 \mathrm{mg} \mathrm{mL}^{-1}\right)$. Após incubação por $20 \mathrm{~min} \mathrm{a} 40^{\circ} \mathrm{C}$, a reação foi paralisada com a adição de $200 \mu \mathrm{L}$ de solução de $\mathrm{HCl} 1 \mathrm{M}$, seguida de resfriamento em gelo por 10 min e centrifugação a $10.000 g$ por $5 \mathrm{~min}$. A absorbância a $600 \mathrm{~nm}$ do sobrenadante foi determinada tendo-se tampão de extração na cubeta de referência. Os resultados foram expressos em unidades de absorbância $\mathrm{min}^{-1} \mathrm{mg}^{-1}$ proteína, descontando-se os valores de absorbância do controle $(800 \mu \mathrm{L}$ de tampão de extração + $200 \mu \mathrm{L}$ de "CM-curdlan-RBB").

\section{Proteínas totais}

O teste de Bradford foi empregado para a quantificação do conteúdo total de proteínas nas amostras (6). Foram adicionados a cada $0,8 \mathrm{~mL}$ de amostra, sob agitação, $0,2 \mathrm{~mL}$ do reagente de Bradford. Após 5 minutos, foi efetuada a leitura da absorbância a $595 \mathrm{~nm}$ em espectrofotômetro. A concentração de proteínas, expressa em termos de equivalentes $\mu \mathrm{g}$ de albumina de soro bovino (ASB) em um $\mathrm{mL}$ de amostra ( $\mu \mathrm{g}$ proteína $\mathrm{mL}^{-1}$ ), foi determinada utilizando-se curva padrão de ASB, variando de 0 a $20 \mu \mathrm{g} \mathrm{mL}^{-1}$.

\section{Lignina e compostos fenólicos}

Amostras de tecido vegetal, foram trituradas em nitrogênio líquido e secas por $6 \mathrm{~h}$ em "Integrated SpeedVac System" modelo ISS 100, marca Savant. Deste material seco, $30 \mathrm{mg}$ foram transferidas para tubo "eppendorf" de $2 \mathrm{~mL}$ e homogenizadas com 1,5 mL de metanol $80 \%$ e extraídas sob agitação por $15 \mathrm{~h}$ em agitador rotativo, protegido da luz e em temperatura ambiente. O extrato metanólico foi centrifugado a $12.000 \mathrm{~g}$ por $5 \mathrm{~min}$ e o sobrenadante foi transferido para novo tubo "eppendorf" para determinação dos compostos fenólicos. O resíduo foi utilizado para quantificação de lignina e polímeros semelhantes. Para tanto, um volume de $1,5 \mathrm{~mL}$ da água destilada foi adicionado ao precipitado, homogeneizado e centrifugado a $12.000 \mathrm{~g}$ por $5 \mathrm{~min}$. O sobrenadante foi descartado e o resíduo foi seco a $65^{\circ} \mathrm{C}$ por $15 \mathrm{~h}$. O resíduo seco insolúvel em álcool, contendo lignina, foi utilizado para determinação de lignina, de acordo com metodologia de Barber \& Ride (1). Um volume de 1,5 mL de solução contendo ácido tioglicólico e $\mathrm{HCl} 2 \mathrm{M}$ (proporção de 1:10) foi adicionado ao resíduo. Os tubos "eppendorf” foram agitados suavemente para hidratar o resíduo e então colocados em banho-maria a $100{ }^{\circ} \mathrm{C}$ por $4 \mathrm{~h}$. Após, os tubos foram mantidos em gelo por $10 \mathrm{~min}$ e centrifugados a $12.000 \mathrm{~g}$ por $10 \mathrm{~min}$, sendo o sobrenadante descartado e o precipitado lavado com $1,5 \mathrm{~mL}$ de água destilada deionizada e novamente centrifugado a $10.000 \mathrm{~g}$ por $10 \mathrm{~min}$. Após, o sobrenadante foi descartado e o precipitado resuspenso em 1,5 $\mathrm{mL}$ de $\mathrm{NaOH} 0,5$ $\mathrm{M}$, sendo a mistura agitada em agitador rotativo por $15 \mathrm{~h} \mathrm{em}$ temperatura ambiente. A mistura foi centrifugada a $10.000 \mathrm{~g}$ por 10 min e o sobrenadante foi transferido para novo tubo "eppendorf", sendo adicionado $200 \mu \mathrm{L}$ de $\mathrm{HCl}$ concentrado ao sobrenadante e mantido em câmara fria $\left(4^{\circ} \mathrm{C}\right)$ por $4 \mathrm{~h}$ para permitir a precipitação da lignina ligada ao ácido tioglicólico. Após, a mistura foi centrifugada a $10.000 \mathrm{~g}$ por $10 \mathrm{~min}$, o sobrenadante descartado e o precipitado resuspenso em $2 \mathrm{~mL}$ de $\mathrm{NaOH} 0,5 \mathrm{M}$. A absorbância desta solução foi determinada a $280 \mathrm{~nm}$ e os valores calculados com base na curva de lignina, sendo expresso em mg de lignina por g de tecido seco (23).

Os compostos fenólicos totais foram determinados pipetando-se $150 \mu \mathrm{L}$ do extrato metanólico, proveniente da determinação de lignina, misturando-se $150 \mu \mathrm{L}$ do reagente de Folin-Ciocalteau $0,25 \mathrm{~N}$ e mantido em temperatura ambiente por $5 \mathrm{~min}$, adicionando-se então $150 \mu \mathrm{L}$ de $\mathrm{Na}_{2} \mathrm{CO}_{3} 1 \mathrm{M}$, sendo homogeneizado e mantido por $10 \mathrm{~min}$ em temperatura ambiente. A mistura foi então homogeneizada com $1 \mathrm{~mL}$ de $\mathrm{H}_{2} \mathrm{O}$ destilada e deionizada e mantida a temperatura ambiente por uma hora. A absorbância da reação foi lida a $725 \mathrm{~nm}$, e os valores de absorbância foram calculados com base em curva de catecol e os compostos fenólicos totais expressos em equivalente mg de catecol por g de tecido seco (23).

\section{Crescimento do feijoeiro}

A massa seca total, após permanência do material vegetal a $60^{\circ} \mathrm{C}$ até peso constante foi obtida pela pesagem das plantas coletadas a partir do décimo quarto dia após a germinação, por ocasião da primeira aplicação dos tratamentos, a segunda coleta sete dias após, a terceira coleta 21 dias após, a quarta coleta 35 dias após e a quinta coleta 49 dias após, dessa forma as coletas foram realizadas sempre sete dias após cada aplicação dos tratamentos.

\section{RESULTADOS E DISCUSSÃO}

\section{Avaliação da doença}

Com o uso dos indutores pôde-se diagnosticar a ocorrência da sistematicidade do controle em feijoeiro contra $X$. axonopodis pv. phaseoli, com base na redução do crestamento bacteriano comum em $79 \%$, com a utilização do ASM e em 37\%, com a utilização de $B$. cereus $(\mathrm{P}<0,01)$ (Tabela 1). O ASM, pelas suas características químicas e semelhança com o ácido salicílico - sinalizador endógeno tendo como efeito na planta a ativação dos mecanismos de resistência. Neste sentido, Bigirimana \& Höfte (2) observaram aumento da resistência do feijoeiro contra Colletotrichum lindemuthianum, e Iriti \& Faoro (15) contra Uromyces appendiculatus, com proteção de até $100 \%$. Contra bactérias fitopatogênicas, apenas Soares \& Maringoni (25) testaram ASM contra Curtobacterium flaccunfaciens pv. flaccunfaciens, mas não encontraram resposta de proteção. O uso de rizobactérias como indutor de resistência na cultura do feijoeiro, foi pesquisado por Bigirimana \& Höfte (2) via tratamento do solo com Pseudomonas fluorescens e $P$. aeruginosa, evidenciando a expressão da resistência induzida pelo seu efeito protetor e Ongena et al. (21) induziram resistência em feijoeiro com Pseudomonas putida e $P$. aeruginosa aplicados ao solo contra Botrytis cinerea, onde observaram 
Tabela 1. Severidade e percentual de controle do crestamento bacteriano causado por X. axonopodis pv. phaseoli em feijoeiro cv. Carioca Tybatã com resistência induzida por acibenzolar-S-metil (ASM) ou Bacillus cereus três dias antes da inoculação, comparados com plantas tratadas apenas com água destilada (controle). Dados transformados por $\sqrt{x+0,5}$.

\begin{tabular}{lcc}
\hline Tratamento & Severidade área lesionada (\%)* & Controle $(\%)$ \\
\hline ASM & $4,7 \pm 1,1 \mathrm{a}$ & 79,1 \\
Bacillus cereus & $14,2 \pm 2,3 \quad \mathrm{~b}$ & 36,8 \\
Controle & $22,5 \pm 3,2 \quad$ c & - \\
\hline C.V. (\%) & 58,4 & \\
Média geral & 13,8 & \\
\hline
\end{tabular}

Letras distintas diferem pelo teste de Tukey a $1 \%$. * Média \pm erro padrão.

redução nos sintomas da doença de 42 e $35 \%$, respectivamente. Não há dados para o patossistema feijoeiro-Xanthomonas axonopodis pv phaseoli, sendo este trabalho a primeira referência com ASM e $B$. cereus como indutores de resistência.

\section{Atividade enzimática}

A atividade das enzimas avaliadas sofreu alterações em função dos tratamentos. A atividade da peroxidase foi influenciada em função do tempo ( $\mathrm{P}<0,01)$, do número de aplicações $(\mathrm{P}<0,01)$ e do indutor $(\mathrm{P}$ $<0,05$ ) (Figura 1). Para o indutor biótico, somente o valor para 4 aplicações exibiu diferença estatística aos 49 dias após o início dos tratamentos (Figura 1A). Para o ASM esse aumento da atividade foi mais nítido, apresentando diferença estatística após a terceira aplicação (35 dias) para o tratamento com 3 aplicações (ASM 3) mantendo a atividade alta até a última coleta e, após a quarta aplicação (49 dias após inicio do tratamento) para os tratamentos com 4 aplicações (Figura 1B).

A atividade da quitinase não foi alterada significativamente com o indutor biótico (Figura 1C). Porém, com a aplicação do indutor abiótico (ASM) nota-se a elevação alcançando diferença significativa após a primeira, segunda aplicações $(\mathrm{P}<0,01)$ e após a terceira aplicação $(\mathrm{P}$ $<0,05$ ) (Figura 1D). Interessantemente, observa-se que após a primeira aplicação, onde todos os tratamentos haviam recebido a mesma dose, os mesmos apresentam atividade significativamente maior do que o controle. Após a segunda aplicação, os tratamentos que receberam a segunda dose (3 e 4 aplicações) continuaram a elevar a atividade mantendo a diferença significativa $(\mathrm{P}<0,01)$. No entanto, o tratamento com 2 aplicações de ASM, voltou a níveis semelhantes ao controle, indicando que a durabilidade do estado de indução proporcionado por ASM era curto, uma vez que, 15 dias após o tratamento, este mecanismo não estava mais ativo. Após a terceira aplicação (35 dias após início do tratamento), no tratamento com 2 aplicações de ASM, a atividade da enzima tendeu a subir, uma vez que recebeu sua segunda e última aplicação, porém apenas o tratamento com 3 aplicações diferiu estatisticamente do controle nessa época de coleta. Já após a quarta aplicação, as atividades foram semelhantes, não ocorrendo diferença (Figura 1D).

A atividade da $\beta$-1,3-glucanase comportou-se de forma muito semelhante a da quitinase. O indutor biótico não proporcionou aumento significativo na atividade desta enzima (Figura 1E), enquanto que o ASM aumentou significativamente a atividade desta enzima, após a primeira aplicação para o tratamento que recebeu 3 aplicações $(\mathrm{P}<$ 0,05). Após a segunda aplicação (21 dias após o inicio do tratamento), os valores nos tratamentos com 3 e 4 aplicações foram significativamente maior do que o controle $(\mathrm{P}<0,01)$, enquanto que após a terceira aplicação (35 dias após o início do tratamento) não houve diferença para nenhum dos tratamentos e na quarta aplicação apenas o tratamento com 4 aplicações foi significativamente maior $(\mathrm{P}$ $<0,05)$. O tratamento com 2 aplicações não diferiu em nenhuma das épocas de coleta (Figura 1F). De modo geral, as médias de cada um dos tratamentos com ASM, aplicados 2, 3 e 4 vezes, independente da época de coleta (interação indutor x quantidade de aplicação), diferiram do controle (ASM 0), em nível de $\mathrm{P}<0,05$ (dado não mostrado).

Nandakumar et al. (19) induziram resistência em arroz com Pseudomonas fluorescens, uma rizobactéria promotora de crescimento, e verificaram a redução da severidade da podridão da bainha causada por Rhizoctonia solani correlacionada com aumento na atividade de peroxidase e quitinase de forma bastante atenuada. Porém, a partir do momento em que as plantas foram desafiadas com o patógeno, a magnitude dessa atividade foi aumentada, o que não aconteceu em plantas que não foram induzidas, mas desafiadas com o patógeno. Isso pode indicar que a expressão mais atenuada da peroxidase e a não observação de diferença significativa para quitinase e $\beta$-1,3-glucanase com $B$. cereus não seja rejeitável como mecanismo direto de resistência, pois neste trabalho o objetivo foi de verificar os custos da indução antes da chegada do patógeno. Estes mecanismos podem ser acionados, apresentando maior expressão a partir do desafio com algum patógeno, e a planta estar pré-condicionada. Silva et al. (24) mostraram que $B$. cereus em tomateiro causou uma super expressão da peroxidase, aumentando em 10 vezes a atividade, ilustrando que dependendo da interação o resultado pode ser bastante variável. Já com ASM, Buzi et al. (7), trabalhando com melão, observaram aumentos na atividade da peroxidase e quitinase correlacionados com aumento da resistência a Didymella bryoniae e Sclerotinia sclerotiorum. Bokshi et al. (3) observaram aumento de $\beta$-1,3-glucanase em batata induzida com ASM, correlacionado com aumento da resistência contra Fusarium semitectum. Iriti \& Faoro (14), trabalhando com feijoeiro induzido com ASM, demonstraram redução de $100 \%$ na ocorrência de ferrugem, causada por Uromyces appendiculatus, e em testes citológicos mostraram alta concentração de $\mathrm{H}_{2} \mathrm{O}_{2}$, indicando alta atividade de peroxidase nas plantas que expressaram resistência.

\section{Síntese de lignina e compostos fenólicos}

O indutor biótico não proporcionou acúmulo de lignina nos tecidos, não sendo possível detectar diferença estatística (Figura 2-A). Já para o indutor ASM, os resultados de todos os tratamentos diferiram estatisticamente do controle (água) após a quarta aplicação (Figura 2B). Iriti \& Faoro (15) observaram a formação de lignina em função do tratamento com ASM, o que pode ser um dos principais mecanismos responsáveis pela resistência do feijoeiro contra $U$. appendiculatus. Segundo Coley et al. (8), a lignificação representa um mecanismo de defesa que implica em grande investimento de fotoassimilados, que por sua vez, não apresentam retorno ao metabolismo, para serem utilizados em outros processos.

O teor de compostos fenólicos foi afetado pela aplicação do indutor ASM, que reduziu a quantidade desses compostos nas folhas das plantas onde foi usado, principalmente após a segunda aplicação (21 dias após o início do tratamento) para os tratamentos que receberam 3 e 4 aplicações, mas no tratamento que recebeu 2 aplicações não foi estatisticamente significativo (Figura 2-D). Nesta fase do experimento, os tratamentos com 3 e 4 aplicações já haviam recebido duas aplicações, enquanto que o tratamento com 2 aplicações haviam recebido apenas uma aplicação (Figura 2C-D). A redução dos compostos fenólicos pode ter ocorrido principalmente a medida que as células foram se tornando lignificadas, uma vez que compostos fenólicos são substrato 
A

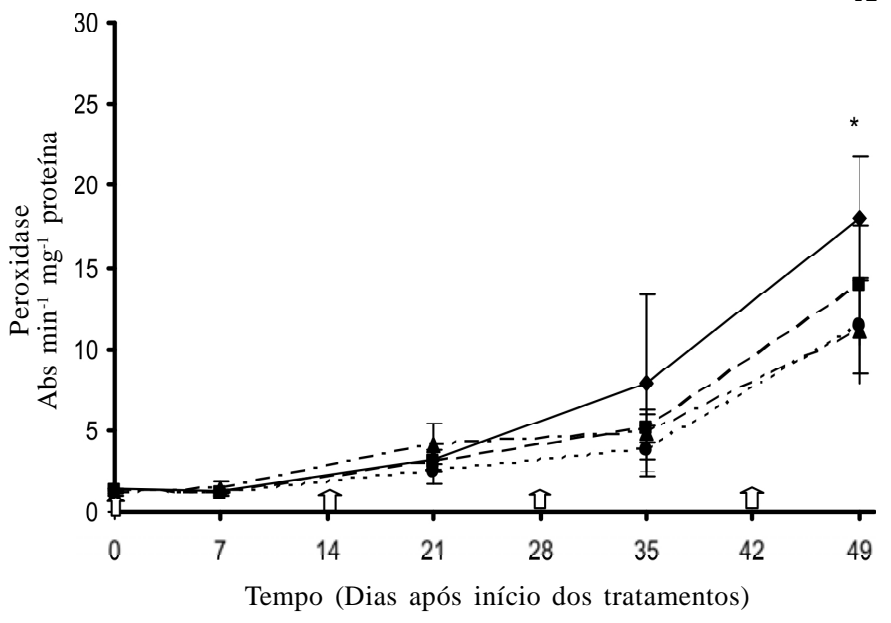

B. cereus

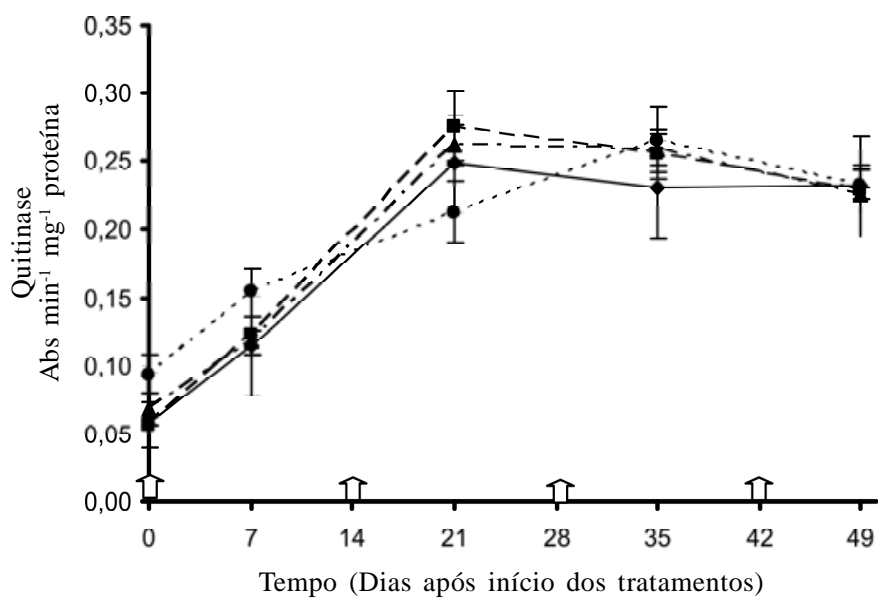

B. cereus

E

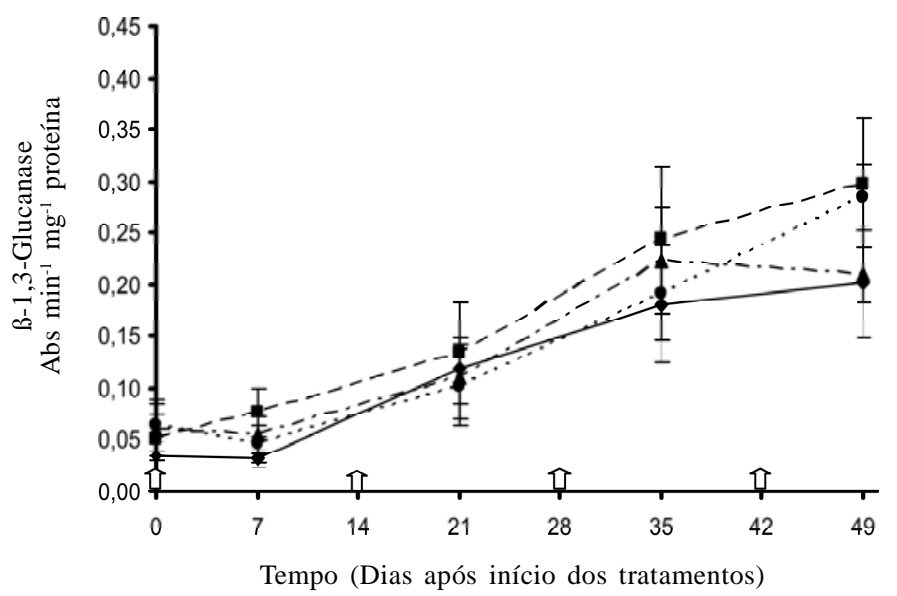

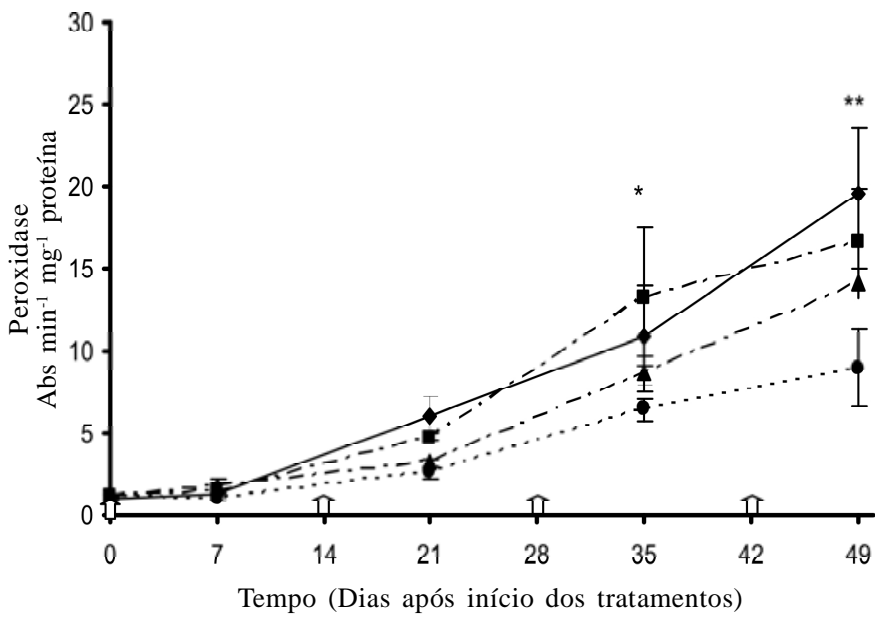

ASM

D

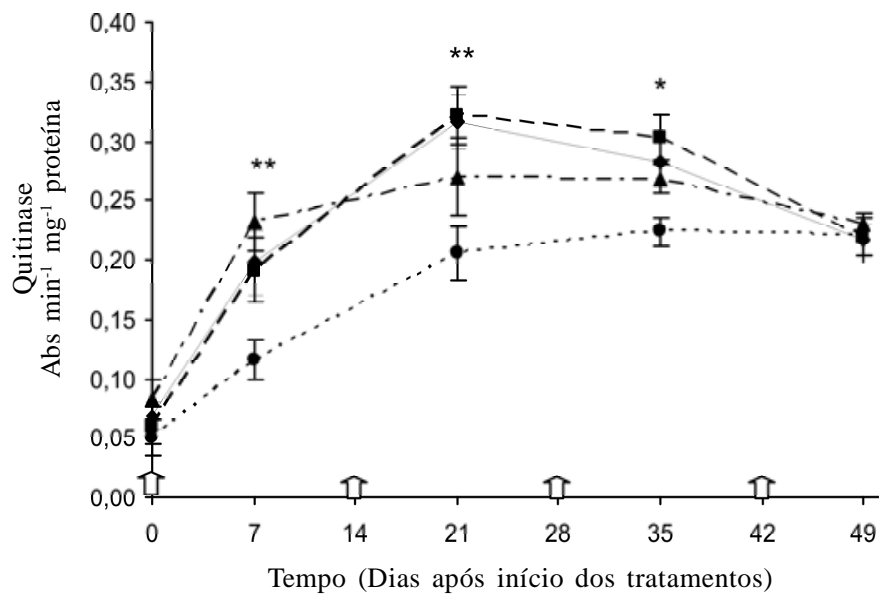

ASM

$\mathbf{F}$

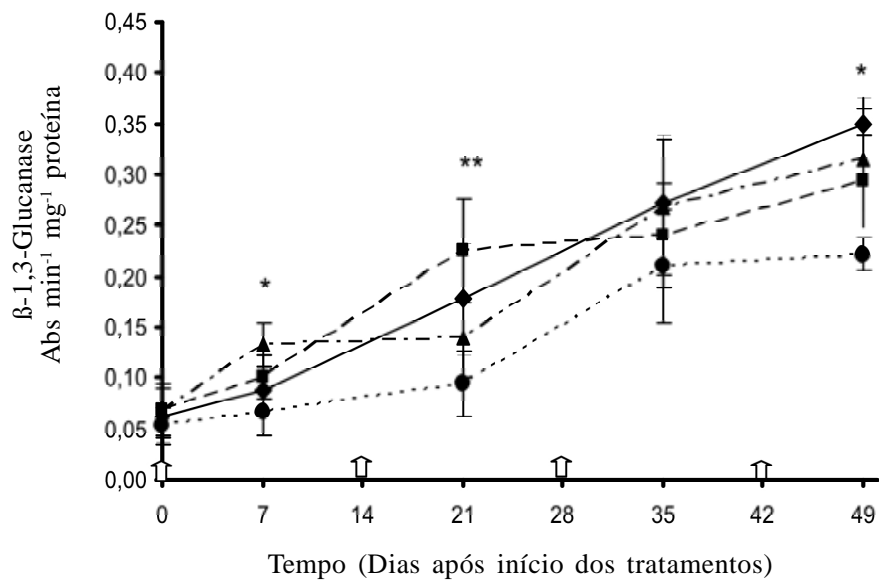

Figura 1. Atividade de peroxidase (A e B), quitinase (C e D) e $\beta$-1,3-glucanase (E e F) em função do tratamento com suspensão de células de Bacillus cereus $\left(10^{8}\right.$ ufc $\left.\mathrm{mL}^{-1}\right)$ ou com solução de acibenzolar-S-metil (ASM) $\left(50 \mathrm{mg}\right.$ i.a. $\left.\mathrm{L}^{-1}\right)$ aplicados $4(\bullet), 3(\boldsymbol{\square}), 2(\boldsymbol{\Delta})$ ou nenhuma $(\bullet)$ vez ao longo do ciclo da cultura. Setas indicam o momento das aplicações (2 aplicações - 0 e $28 ; 3$ aplicações - 0, 14 e 28 e 4 aplicações - 0, 14,28 e 42 dias após o início). Barras indicam a média \pm o erro padrão. * Indica diferença estatística a $5 \%$ e ** a $1 \%$ pelo teste de Tukey. Valores correspondem a média de dois experimentos conduzidos nos anos de 2004 e 2005. Dados de $\beta$-1,3-glucanase transformados por $\sqrt{x+0,01}$ 
B. cereus

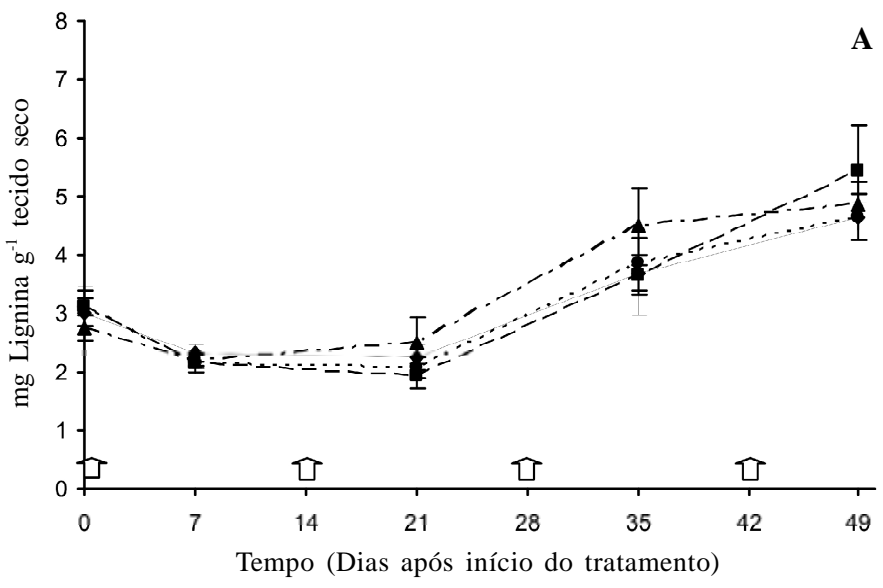

B. cereus

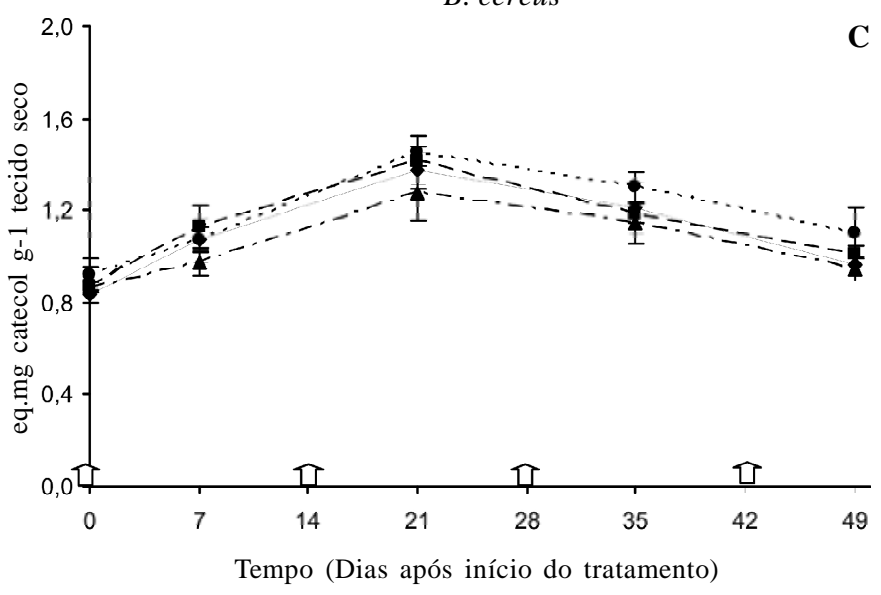

ASM

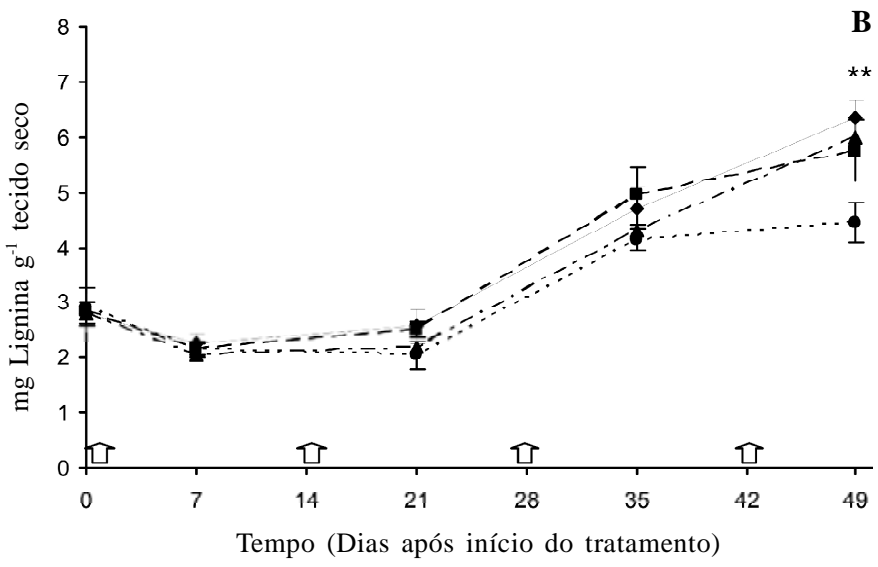

ASM

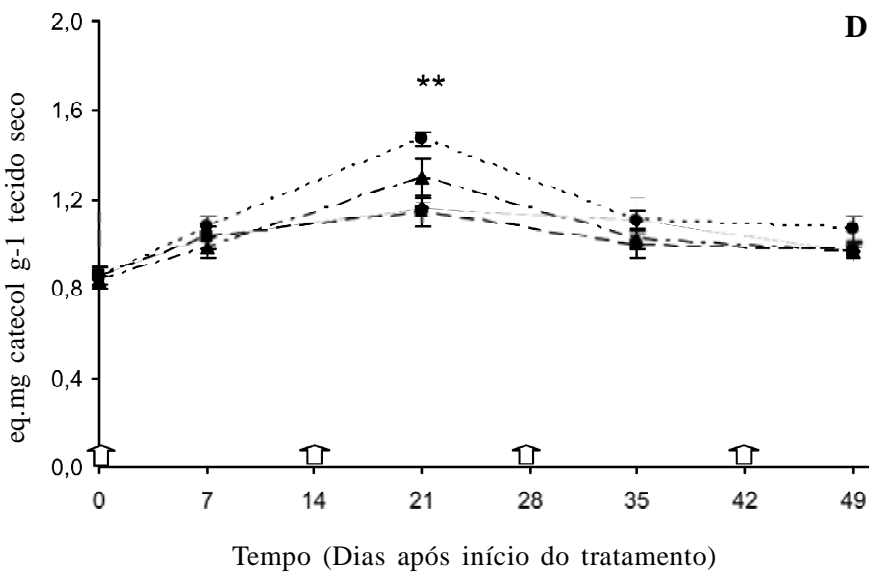

Figura 2. Teor de lignina (A e B) e compostos fenólicos (C e D) em função do tratamento com suspensão de células de Bacillus cereus (10 ufc $\left.\mathrm{mL}^{-1}\right)$ ou com solução de acibenzolar-S-metil (ASM) $\left(50 \mathrm{mg}\right.$ i.a. $\left.\mathrm{L}^{-1}\right)$ aplicados $4(\bullet), 3(\boldsymbol{\square}), 2(\boldsymbol{\Delta})$ ou nenhuma $(\boldsymbol{\bullet})$ vez ao longo do ciclo da cultura. Setas indicam o momento das aplicações (2 aplicações - 0 e 28; 3 aplicações - 0,14 e 28 e 4 aplicações - 0, 14,28 e 42 dias após o início do tratamento). Barras indicam a média \pm o erro padrão. ** Indica diferença estatística a $1 \%$ pelo teste de Tukey.

para a síntese de lignina pela ação da peroxidase. Embora os compostos fenólicos sejam considerados como mecanismos de defesa das plantas, não é o caso do feijoeiro induzido por ASM, na condição estudada. Da mesma forma também não é o mecanismo induzido por $B$. cereus, visto que não se observa diferença significativa (Figura 2-C).

\section{Crescimento}

O acúmulo de massa seca por parte da planta ao longo do seu ciclo não foi afetado pela presença do indutor biótico, não mostrando diferença estatística (Figura 3A). No entanto, os tratamentos que receberam 3 e 4 aplicações de ASM diferiram estatisticamente após a terceira aplicação (35 dias) ( $\mathrm{P}<0,01)$. Após a quarta aplicação (49 dias), o tratamento com 4 aplicações de ASM reduziu a massa seca a ponto de se diferenciar $(\mathrm{P}<0,01)$ não apenas do controle, mas também dos outros tratamentos ( 2 e 3 aplicações), enquanto que o tratamento com 2 aplicações de ASM não foi afetado o suficiente para se diferenciar estatisticamente do controle, porém, notando-se uma nítida tendência a redução (Figura 3B).

A redução no crescimento também foi observado por Godard et al. (10), que induziram resistência em couve-flor contra míldio (Peronospora) com ASM em diferentes concentrações em uma única aplicação. $\mathrm{O}$ crescimento foi reduzido de forma dependente da dose utilizada, sendo que todas as doses reduziram o crescimento. Com 1,5 $\mathrm{mg}$ i.a. $\mathrm{L}^{-1}$ essa redução foi de $6 \%$ sem, no entanto, reduzir a severidade da doença. Porém, com a dose de $75 \mathrm{mg}$ i.a. $\mathrm{L}^{-1}$ o crescimento foi reduzido em $25 \%$ com redução da severidade em $80 \%$. Heil et al. (13), trabalhando com trigo induzido com ASM (150 mg i.a. $\left.\mathrm{L}^{-1}\right)$ em dose única, observaram redução do crescimento em função da concentração de nitrogênio disponível, ou em função do estádio fenológico da cultura no momento da indução. Dietrich et al. (9), trabalhando com Arabidopsis induzida por ASM (150 mg i.a. $\left.\mathrm{L}^{-1}\right)$, observaram redução no crescimento em função da concentração de nitrogênio e da água disponíveis. Em feijoeiro, Iriti \& Faoro (15) induziram resistência com ASM (140 mg i.a. $\mathrm{L}^{-1}$ ) em uma única aplicação e, não detectaram diferenças na taxa de crescimento, comprimento de entrenós e expansão foliar ao longo do ciclo em casa de vegetação. Já com indutor biótico, Ongena et al. (20), trabalhando com pepino submetido ao indutor biótico Pseudomonas putida, observaram acentuada redução da severidade de Pythium aphanidermatum, porém, não houve redução da massa fresca de parte aérea e ocorreu aumento da massa seca de raízes das plantas induzidas.

A indução de resistência a partir do indutor biótico, B. cereus, 

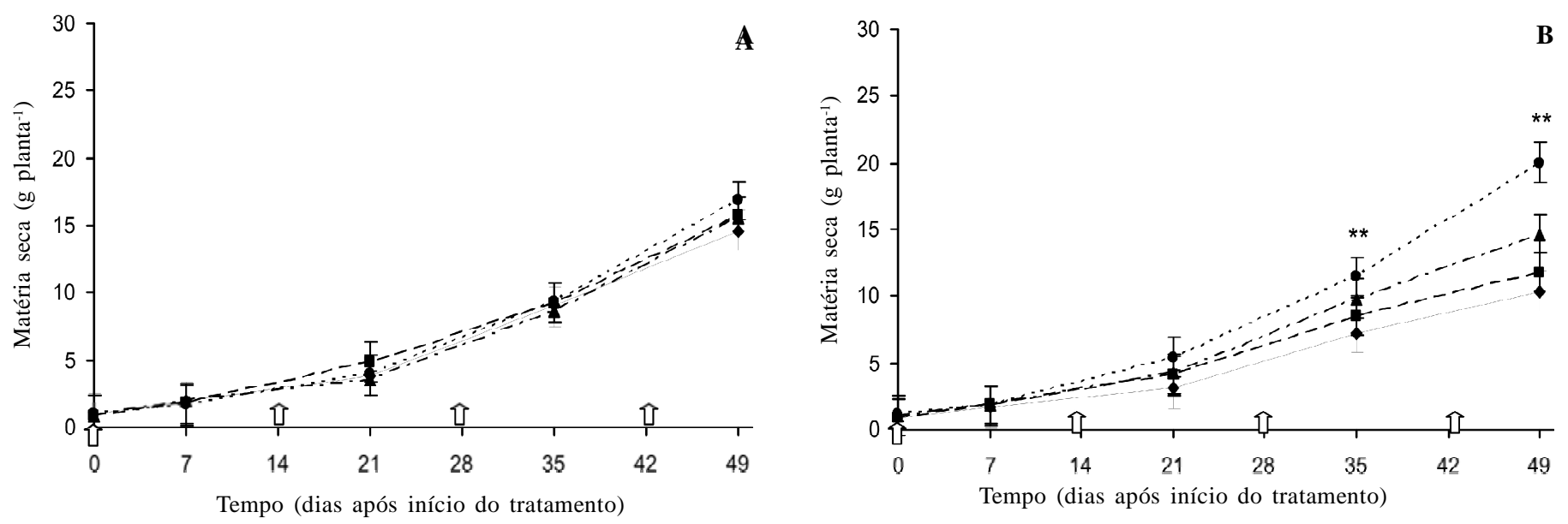

Figura 3. Matéria seca de parte aérea do feijoeiro ao longo do ciclo em função do tratamento com suspensão de células de Bacillus cereus $\left(10^{8} \mathrm{ufc} \mathrm{mL}^{-1}\right)$ ou com solução de acibenzolar-S-metil (ASM) $\left(50 \mathrm{mg}\right.$ i.a. $\left.\mathrm{L}^{-1}\right)$ aplicados $4(\boldsymbol{\bullet}), 3(\boldsymbol{\square}), 2(\boldsymbol{\Delta})$ ou nenhuma $(\boldsymbol{O})$ vez ao longo do ciclo da cultura. Setas indicam o momento das aplicações ( 2 aplicações - 0 e 28; 3 aplicações - 0, 14 e 28 e 4 aplicações $-0,14,28$ e 42 dias após o início). Barras indicam a média \pm o erro padrão. ** Indica diferença estatística a $1 \%$ pelo teste de Tukey. Valores correspondem a média de dois experimentos conduzidos nos anos de 2004 e 2005.

alterou o metabolismo da planta de maneira mais sutil pelo aumento da peroxidase sem interferir no acúmulo de massa seca, enquanto que o indutor abiótico ASM alterou o metabolismo da planta, demonstrado pelo aumento na atividade de peroxidase, quitinase e $\beta$-1,3-glucanase, assim como no teor de ligninina, gerando um custo metabólico para investir em defesas, ao custo da redução do crescimento.

\section{Agradecimentos}

Os autores agradecem ao Prof. Dr. Reginaldo da Silva Romeiro (in memoriam) do Laboratório de Bacteriologia de Plantas da Universidade Federal de Viçosa por ter fornecido o isolado de B. cereus, ao Instituto Agronômico de Campinas por ter fornecido a semente de feijão cv. Carioca Tybatã e ao Conselho Nacional de Desenvolvimento Científico e Tecnológico - CNPq, pela concessão de bolsa.

\section{REFERÊNCIAS BIBLIOGRÁFICAS}

1. Barber, M.S.; Ride, J.P. A quantitative assay for induced lignification in wounded wheat leaves and its use to survey potential elicitors of the response. Physiological and Molecular Plant Pathology, London, v.32, p.185-1197, 1988.

2. Bigirimana, J.; Höfte, M. Induction of systemic resistance to Colletotrichum lindemuthianum in bean by a benzothiadiazole derivative and rhizobacteria. Phytoparasitica, Bet Dagan, v. 30, p.154-168, 2002.

3. Bokshi, A.I.; Morris, S.C.; Deverall, B.J. Effects of benzothiadiazole and acetylsalicylic acid on $\beta$-1,3-glucanase activity and disease resistance in potato. Plant Pathology, London, v.52, p.22-27, 2003.

4. Bonaldo, S.M.; Pascholati, S.F., Romeiro, R.S. Indução de resistência: noções básicas e perspectivas. In: Cavalcanti, L.S.; Di Piero, R.M.; Cia, P.; Pascholati, S.F.; Resende, M.L.V.; Romeiro, R.S. Indução de resistência em plantas a patógenos e insetos. Piracicaba: FEALQ, 2005, p.11-28.

5. Bostock, R.M. Signal crosstalk and induced resistance: straddling the line between cost and benefit. Annual Review of Phytopathology, Palo Alto, v. 42, p. 545-580, 2005.

6. Bradford, M. A rapid and sensitive method for the quantitation of microgram quantifies of protein utilizing the principle of pro- tein-dye binding. Analytical Biochemistry, New York, v.72, p.248-254, 1976.

7. Buzi, A.; Chilosi, G.; De Sillo, D.; Magro, P. Induction of resistance in melon to Didymella bryoniae and Sclerotinia sclerotiorum by seed treatment with salicylic acid. Journal of Phytopathology, Berlin, v.152, p.34-42, 2004.

8. Coley, P.D.; Bryant, J.P.; Chapin, F.S. Resource availability and plant antiherbivore defense. Science, Washington, v.230, p.895$899,1985$.

9. Dietrich, R.; Ploss, K.; Heil, M. Growth responses and fitness cost after induction of pathogen resistance depend on environmental condition. Plant Cell and Environment, Oxford, v.28, p.211-222, 2005.

10. Godard, J-F.; Ziadi, S.; Monot, C.; Le Corre, D.; Silué, D. Benzothiadiazole (BTH) induces resistance in cauliflower (Brassica oleracea var botrytis) to downy mildew of crucifers caused by Peronospora parasitica. Crop Protection, Guildford, v.18, p.397405, 1999.

11. Guzzo, S.D.; Martins, E.M.F. Local and systemic induction of $\beta$ 1,3-glucanase and chitinase in coffee leaves protected against Hemileia vastatrix by Bacillus thuringiensis. Journal of Phytopathology, Berlin, v.144, n.9/10, p.449-454. 1996.

12. Heil, M. Ecological costs of induced resistance. Current Opinion in Plant Biology, London, v.5, p.1-6, 2002.

13. Heil, .M; Hilpert, A.; Kaiser, W.; Linsenmair, K.E. Reduced growth and seed set following chemical induction of pathogen defence: does systemic acquired resistance (SAR) incur allocation cost? Journal of Ecology, Oxford, v.88, p.645-654, 2000.

14. Iriti, M.; Faoro, F. Benzothiadiazole (BTH) induces cell-death independent resistance in Phaseolus vulgaris against Uromyces appendiculatus. Journal of Phytopathology, Berlin, v.151, p.171-180, 2003.

15. Iriti, M.; Faoro, F. Does benzothiadiazole-induced resistance increase fitness cost in bean? Journal of Plant Pathology, Bari, v.85, n.4 special issue, p.265-270, 2003.

16. Kado, C. I.; Heskett, M. G. Selective media for isolation of Agrobacterium, Corynebacterium, Erwinia, Pseudomonas and Xanthomonas. Phytopathology, Lancaster, v.60, p.969-976, 1970.

17. Louws, F.J.; Wilson, M.; Campbell, H.L.; Cuppels, D.A.; Jones, J.B.; Shoemacker, P.B.; Sahin, F.; Miller, S.A. Field control of bacterial spot and bacterial speck of tomato using a plant activator. Plant Disease, Saint Paul, v.85, p.481-488, 2001.

18. Lusso, M.F.G.; Pascholati, S.F. Activity and isoenzymatic pattern of soluble peroxidases in maize tissues after mechanical injury or 
fungal inoculation. Summa Phytopathologica, Botucatu, v.25, p.244-249, 1999.

19. Nandakumar, R.; Babu, S.; Viswanathan, R.; Raguchander, T.; Samiyappan, R. Induction of systemic resistance in rice against sheath blight disease by Pseudomonas fluorescens. Soil Biology \& Biochemistry, Oxford, v.33, p.603-612, 2001.

20. Ongena, M.; Daayf, F.; Jacques, P.; Thonart, P.; Benhamou, N.; Paulitz, T.C.; Cornélis, P.; Koedam, N.; Bélanger, R.R. Protection of cucumber against Pythium root rot by fluorescent pseudomonads: predominant role of induce resistance over siderophores and antibiosis. Plant Pathology, London, v.48, p.66-76, 1999.

21. Ongena, M.; Giger, A.; Jacques, P.; Dommes, J.; Thonart, P. Study of bacterial determinants involved in the induction of systemic resistance in bean by Pseudomonas putida BTP1. European Journal of Plant Pathology, Dordrecht, v.108, p.187-196, 2002 .

22. Redman, A.M.; Cipollini Júnior, D.F.; Schultz, J.C. Fitness costs of jasmonic acid-induced defense in tomato, Lycopersicon esculentum. Oecologia, Berlin, v.126, p.380-385, 2001.

23. Rodrigues, F.A.; Jurick II, W.M.; Datnoff, L.E.; Jones, J.B.; Rollins, J.A. Silicon influences cytological and molecular events in compatible and incompatible rice-Magnaporthe grisea interactions. Physiological and Molecular Plant Pathology, London, v. 66, p. $144-159,2005$.

24. Silva, H.S.A.; Romeiro, R.S.; Macagnan, D.; Halfeld-Vieira, B.A.; Pereira, M.C.B.; Mounteer, A. Rhizobacterial induction of systemic resistance in tomato plants: non-specific protection and increase in enzyme activities. Biological Control, Orlando, v.29, p.288-295, 2003.

25. Soares, R.M.; Maringoni, A.C. Efeito de acibenzolar-S-metil sobre a germinação e desempenho de sementes de feijoeiro e na indução de resistência à murcha-de-curtobacterium. Summa Phytopathologica, Botucatu, v.28, p.41-45, 2002.

26. Stangarlin, J.R.; Pascholati, S.F.; Labate, C.A. Efeito de Phaeoisariopsis griseola na atividade de ribulose-1,5-bifosfato carboxilase-oxigenase, clorofilase, $\beta$-1,3-glucanase e quitinase em cultivares de Phaseolus vulgaris. Fitopatologia Brasileira, Brasília, v.25, p.59-66, 2000.

27. Vale, F.X.R.; Fernandes Filho, E.I.; Liberato, J.R. Quant - A software for plant disease severity assessment. $8^{\text {th }}$ International Congress of Plant Pathology. Christchurch, New Zealand, 2-7 de fevereiro, p.105, 2003.

28. Wirth, S.J.; Wolf, G.A. Micro-plate colorimetric assay for endoacting cellulase, xylanase, chitinase, 1,3- $\beta$-glucanase and amylase extracted from forest soil horizons. Soil Biology and Biochemistry, Oxford, v.24, p.511-519, 1992. 